\title{
Anaesthesia mumps after total laparoscopic hysterectomy under general anaesthesia
}

\author{
Prabha Udayakumar ${ }^{1 *}$, Kanmani Mani $^{2}$, Hemaamallene $\mathbf{P .}^{1}$
}

\author{
${ }^{1}$ Department of Anaesthesiology, Sri Ramakrishna Hospital, Coimbatore, Tamil Nadu, India \\ ${ }^{2}$ Department of Obstetrics and Gynaecology, Sri Ramakrishna Hospital, Coimbatore, Tamil Nadu, India
}

Received: 09 February 2021

Accepted: 24 February 2021

\author{
*Correspondence: \\ Dr. Prabha Udayakumar, \\ E-mail: prabhadr01@gmail.com
}

Copyright: (c) the author(s), publisher and licensee Medip Academy. This is an open-access article distributed under the terms of the Creative Commons Attribution Non-Commercial License, which permits unrestricted non-commercial use, distribution, and reproduction in any medium, provided the original work is properly cited.

\begin{abstract}
Anaesthesia mumps is a rare clinical entity characterised by acute transient swelling of the parotid gland in postoperative period. In our case a 58 years obese lady developed left sided parotid swelling which was managed conservatively and settled without any sequelae. In this article we discuss possible causes, differential diagnosis and treatment for this condition. This is to increase awareness about this relatively unknown condition amongst anaesthetist and surgeons and to avoid unnecessarily apprehension in post-operative period.
\end{abstract}

Keywords: Anaesthesia mumps, Post-operative parotitis, Acute transient swelling, Pneumoparotitis, Ischemic sialadenitis, Trendelenburg position, Total laparoscopic hysterectomy

\section{INTRODUCTION}

Acute parotitis also referred as 'anaesthesia mumps' is a rare under reported complication observed after GA. ${ }^{1}$ This was first reported by Atlas et al although reported commonly after general anaesthesia (GA) complication can be seen under regional anaesthesia where the probable cause is position related. ${ }^{2,3}$ It usually presents as bilateral swelling, although rare, cases of unilateral sialadenitis also have been reported in literature as seen in our case. ${ }^{4,5}$

\section{CASE REPORT}

We report acute sialadenitis of left parotid gland after total laparoscopic hysterectomy (TLH) under GA in a 58 years old obese lady with body weight of $87 \mathrm{~kg}$ and BMI of 33.98 .

Patient was posted for TLH for post-menopausal bleeding. During pre-anaesthesia check-up, patient was found to be a known case of hypertension for which she was on tablet chlorthalidone 6.25 OD and her blood pressure was under control. She didn't give history of any facial swelling, calculi in salivary gland or mumps in the past. Her blood investigations were within normal limits. She underwent cardiac evaluation with echocardiography and was accepted for anaesthesia under ASA II.

Patient reassessed on the day of surgery and premedicated with injection glycopyrrolate $0.2 \mathrm{mg}$, injection ondansetron $4 \mathrm{mg}$ and injection midazolam 2 mg. Patient shifted to OT, connected to standard monitors and preoxygenated with $100 \% \mathrm{O}_{2}$. Induction was done with injection propofol $120 \mathrm{mg}$ and Fentanyl $100 \mathrm{ugm}$. Endotracheal intubation was facilitated by using injection atracurium $45 \mathrm{mg}$ and after obtaining adequate muscle relaxation patient was intubated smoothly in one attempt using Macintosh blade no. 3 and ETT of 7.0 ID and tube was secured in place with plaster after confirming bilateral equal air entry.

Anaesthesia was maintained by oxygen $50 \%$ in air and sevoflurane and injection dexmedetomidine 0.5 $\mathrm{ugm} / \mathrm{kg} / \mathrm{hr}$ as an infusion. MAC was maintained between 1 to1.5 depending on the surgical requirements. IPPV 
was given with volume-controlled mode with TV of 500 $\mathrm{ml}$ and respiratory rate of $14 / \mathrm{min}$. Eyes were covered and neck stabilised in neutral position and then patient was placed in lithotomy position with left arm secured by the side and Trendelenburg $45^{\circ}$ given as per the gynaecologist preference. Throughout the surgery head was in neutral position stabilised over the gel pad.

Intra operatively muscle relaxation was maintained with injection atracurium $10 \mathrm{mg}$ every 30 mins. Patient was monitored for NIBP, ECG, $\mathrm{SpO}_{2}, \mathrm{MAC}, \mathrm{ETCO}_{2}$, temperature and urine output. $\mathrm{BP}$ was maintained within normal ranges with MAP between $65-80 \mathrm{mmHg}$. There was no incidence of intraoperative hypotension and lowest recorded BP was 100/60 mmHg. Total of 1.5 litres IV fluids were given including 1 unit of NS and 2 units of RL and urine output was $200 \mathrm{ml}$ at the end of surgery. Surgery lasted for 2 hours and patient was reversed with injection glycopyrrolate $0.5 \mathrm{mg}$ and injection neostigmine $2.5 \mathrm{mg}$. Extubation was smooth and uneventful. Patient was monitored in recovery room for 1 hour and then shifted to the postsurgical unit.

On first postoperative day, patient complained of pain in left preauricular region to the gynaecologist who noticed a diffuse swelling in the parotid region. On local examination, swelling was soft with smooth surface, mild tenderness with no signs of inflammation and there were no crepitations. Patient was managed with intravenous fluids, antibiotics, anti-inflammatory drugs and reassurance. Post-operative investigation in terms of blood counts was normal and clinical diagnosis of anaesthesia mumps was made which was confirmed by Ultrasound. Swelling subsided over the next $48 \mathrm{hrs}$ and there were no further complaints and patient was discharged home uneventfully.

\section{DISCUSSION}

Acute sialadenitis was described and reported by Atlas et al in 1968 and later named as anaesthesia mumps by Reily et al in 1971. ${ }^{1,2}$ It is described as a benign self-limiting enlargement of parotid gland appearing after GA, although most commonly reported in peri operative period a case has been reported from ICU. ${ }^{6}$

Various causes have been implicated in this condition which includes positioning during surgery, obesity, drugs, hypothyroidism etc. ${ }^{7}$

Positioning during surgery has been pointed out as an important cause for this condition, most important being prone, sitting, head extension, left decubitus where there is mechanical obstruction to salivary gland out flow or blockage of Stenson's duct. ${ }^{4,5,8}$ Compression due to shoulder braces after robotic total hysterectomy has been reported. ${ }^{10}$

Various drugs are also implicated which acts by either increasing the salivary gland secretions or decreasing the out flow because of ductal spasm. Drugs like anticholinergics, benzodiazepines, ketamine, succinylcholine are implicated.

Pneumoparotitis a condition defined as retrograde air entry into the parotid gland through Stenson's duct during positive intra oral pressures as seen during coughing, straining and mask ventilation. ${ }^{11}$ In our case there were no crepitations over swelling ruling out pneumoparotitis.

Mechanical trauma with laryngoscope blade and oral airways leads to direct injury to laryngeal structures causing bleeding and post-operative edema has also been postulated as one of the causes behind this condition. Other possible cause enumerated is ischemic sialadenitis resulting from positioning leading to compression of vascular supply of the gland.

In our case the probable cause of sialadenitis is prolonged head low position in obese patient. Although reported with other positions, this is the first time a case of anaesthesia mumps has been reported with steep Trendelenburg position. Since left arm was tucked so inadvertent left side head tilt leading to mechanical ductal blockage is one of the possibilities. Other probable cause can be use of glycopyrrolate, midazolam or dehydration in the postoperative period.

We report this case to increase awareness about this selflimiting benign condition to avoid unnecessary apprehension to patient, surgeon and anaesthetist. Although benign condition resolving within 2-3 days of surgery, a case of massive facial edema and airway obstruction has been reported. ${ }^{12}$ A case of transient facial nerve palsy following anaesthesia mumps in a 3-year-old child has been reported. ${ }^{13}$

\section{CONCLUSION}

So, we recommend strict attention to detail during positioning the patient, especially for prolonged surgeries. Head should always be in the neutral position and precautions taken to avoid extremes of head extension, flexion and lateral tilting. We insist the importance of limiting trauma while performing laryngoscopy, intubation, extubation and use of oral airways. Maintenance of adequate hydration of the patient in perioperative period is equally important.

\section{Funding: No funding sources \\ Conflict of interest: None declared \\ Ethical approval: Not required}

\section{REFERENCES}

1. Reily DJ. Benign transient swelling of parotid glands following general anaesthesia: anaesthesia mumps. Anaesth Analog. 1970;49:560-3. 
2. Atlas M, Sabawala PB, Keats AS. Acute transient sialadenopathy during induction of anaesthesia. Anaesthesiol. 1968;29:1050-2.

3. Piart A, Camkiran A, Bulci ST, Zeyneloglu P, Kayhan Z. Bilateral submandibular salivary glands swelling following regional anaesthesia after hip replacement. Acta Anesthesiol Scand. 2009;53:272.

4. Hans P, Demoitie J, Colingnon L, Bex V, Bonhomme V. Acute bilateral submandibular swelling following surgery in prone position. EUR J Anaesthesiol. 2006;23:83-4.

5. Postaci A, Aytae I, Oztekm CV, Dikmen B. Acute unilateral parotid glands swelling after lateral decubitus position under general anaesthesia. Saudi J Anaesth. 2012;6:295-7.

6. Ghatak T, Gurjar M, Samonta S, Baronia A. A case of anaesthesia mumps from ICU. Saudi J Anaesth. 2013;7:222-3.

7. Narang J, Trikha A, Chandralekha C. Anaesthesia mumps and morbid obesity. Acta Anasthesiol Belg. 2010;61:83-5.

8. Berker M, Sahin A, Aypar U, Ozgen T. Acute parotids following sitting position neurosurgical procedures: review of five cases. J Neurosurg Anaesthesiol. 2004;16:29-31.
9. Izci Y, Crdogen E, Timurkayanak E. Acute right submadibular swelling following surgery for bilateral optic nerve meningioma. J Neurosurg Anaesthesiol. 2005; 17:58-9.

10. Lee JM, Park EY, Kim KM, Won JC, Kim YJ, Kyung S. Bilateral anaesthesia mumps after robot assisted hysterectomy under general anaesthesia: two case reports. J surg. 2018;6:50-2.

11. Calcaterra TR, Lowe J. Pneumoparotitis. Acta Otolaryngol. 1962;52:784-9.

12. Cavaliere F, Conti G, Anetta MG, Greco A, Cina A, Proietti R. Massive facial edema and airway obstruction secondary to acute postoperative sialadenitis "anaesthesia mumps" a case report. J Med Case Rep. 2009;3:70-3.

13. Ozdek A, Bayir O, Isik ME, Tatar EC, Saylam, Kockmaz H. Anaesthesia mumps resulting in temporary facial nerve palsy after the auditory brainstem implantation in a 3-year-old child. Int $\mathbf{J}$ Pediatr Otorhinolangol. 2014;78:159-62.

Cite this article as: Udayakumar P, Mani K, Hemaamallene P. Anaesthesia mumps after total laparoscopic hysterectomy under general anaesthesia. Int J Reprod Contracept Obstet Gynecol 2021;10:1695-7. 